References

1. Dixit A. Letter to the Editor re The economic cost of schizophrenia in Ireland. Ir J Psych Med 2008; 25(4): 157-60.

2. Behan C, Kennelly B O'Callaghan E. The economic cost of schizophrenia in Ireland. Ir J Psych Med 2008; 25(3): 80-87.

3. Craig TK, Garety P, Power P et al. The Lambeth Early Onset (LEO) Team: randomised controlled trial of the effectiveness of specialised care for early psychosis. BMJ 2004 329(7474): 1067.

4. Goldberg K, Norman R, Hoch JS, Schmitz N, Windell D, Brown N, Malla A. Impact of a specialized early intervention service for psychotic disorders on patient characteristics, service use, and hospital costs in a defined catchment area. Can J Psychiatry 2006; 51(14): 895-903.

5. Bertelsen $M$, Jeppesen $P$, Petersen $L$ et al. Five-year follow-up of a randomized multicenter trial of intensive early intervention vs standard treatment for patients with a first episode of psychotic illness: the OPUS trial. Arch Gen Psychiat 2008; 65(7): $762-71$.

6. Access Economics Pty Limited. Cost effectiveness of early intervention for psychosis. Report for Orygen Research Centre, Melbourne, Australia, 2008.

7. Mihalopoulos C, Harris M, Henry L, Harrigan S. McGorry P. Is early intervention in psychosis cost-effective over the long term? Schiz Bull 2009 Jun 9. DOI: 10.1093/ schbul/sbp054

\section{The Dissociative Experiences Scale: Replacement items for use with the profoundly deaf}

Dear Editor, A range of self-report instruments now exist to measure frequency and types of dissociative experiences. The Dissociative Experiences Scale (DES ${ }^{1}$ ), a 28-item instrument that measures a wide variety of dissociative phenomena (eg. absorption, imaginative involvement, depersonalisation, derealisation, amnesia) is the most frequently used. ${ }^{2}$

Recently, Lewis et $\mathrm{al}^{3}$ have argued that as dissociation is associated with altered sensory perceptions, current instruments designed to measure dissociation, including the DES, are unsuitable for use with the visually impaired given the wording of a number of items, as they make reference either directly or indirectly to the sense of vision. They proposed that in such cases, the DES be amended by replacing six items identified by three clinicians as being unsuitable for this population (items $1,7,11,17,26$, and 28 ) with suitably equivalent ones re-written by the authors to be functionally equivalent to the original items, and be appropriate for use among the visually impaired. Exploratory psychometric research using the replacement items has provided satisfactory results in terms of reliability and validity of such an amended form of the DES and this revised version has been recommended for use in clinical settings. ${ }^{4}$

Since undertaking this work, ${ }^{3,4}$ it has become apparent within our clinical practice that the initial focus of our research, namely amending the DES for use with the visually impaired was too limited and unnecessarily restricted in scope. Specifically, as dissociation is associated with altered sensory perceptions, current measures of dissociation, including the DES, are unsuitable not only for use with the visually impaired, but also for those who have other sensory impairments, including those who are profoundly deaf.

Therefore there was a clear rationale to revise the DES for use among the profoundly deaf. One clinician and one clinical researcher independently identified three of the 28 DES items as being unsuitable for the profoundly deaf, as they made reference either directly or indirectly to the sense of hearing $(2,21$, and 27$)$. These three items were subsequently rewritten by the authors to be functionally equivalent to the original

\section{Table 1: Three items of the DES (original and revised versions items)}

Original item 2: Some people find that sometimes they are listening to someone talk and they suddenly realise that they did not hear part or all of what was said.

New equivalent item 2: Some people find that sometimes they are watching someone talk and they suddenly realise that they did not take in part or all of what was said.

Original item 21: Some people sometimes find that when they are alone they talk out loud to themselves.

New equivalent item 21: Some people sometimes find that when they are alone they communicate 'out loud' to themselves, as if they were speaking to another person.

Original item 27: Some people sometimes find that they hear voices inside their head that tell them to do things or comment on things that they are doing.

New equivalent item 27: Some people sometimes find that they hear things inside their head that tell them what to do or comment on what they are doing.

items, and be appropriate for use among the profoundly deaf. Table 1 contains the three original items alongside the new items that were designed to replace them.

Further work is now required to examine the reliability and validity of the three new replacement items. This would involve the administration of the original 28 items of the DES, along with the three new items, to a sample with normal hearing. This would allow for the statistical examination of the association between each of the three new items with those items they were designed to replace. Providing the three new items were found to be valid replacements, the amended version of the DES can be recommended for use among the profoundly deaf, either by clinical administration or by self-report.

Christopher Alan Lewis, Professor of Psychology, Division of Psychology, Institute for Health, Medical Science and Society, Glyndwr University, Plas Coch Campus, Mold Road, Wrexham, LL11 2AW, Wales, UK. Email: ca.lewis@glyndwr.ac.uk

Martin J Dorahy, Senior Lecturer Department of Psychology, University of Canterbury, Private Bag 4800, Christchurch 8140, New Zealand.

Mary Jane Lewis, Research Associate, Sally-Anne Baker, Senior Lecturer, Division of Psychology, Institute for Health, Medical Science and Society, Glyndwr University, Plas Coch Campus, Mold Road, Wrexham, LL11 2AW, Wales, UK

\section{References}

1. Bernstein EM, Putnam FW. Development, reliability, and validity of a dissociation scale. J Nerv Ment Dis 1986; 174: 727-735.

2. Carlson EB. Trauma assessment: A clinician's guide. New York: Guilford Press, 2007.

3. Lewis CA, Dorahy MJ, O'Rawe B, O'Rawe A. The Dissociative Experiences Scale: Replacement items for use with the visually impaired. Irish J Psych Med 2006; 23 121-122. (Letter)

4. Lewis CA, Dorahy MJ, O'Rawe B, O'Rawe A. The Dissociative Experiences Scale: Reliability and validity of amended version for the visually impaired. (Abstract). The British Psychological Society Conference, City Hall, Cardiff, Wales, March 30-April 1, 2006. Proceedings of the British Psychological Society. Retrieved, January 20, 2010, from www.bps.org.uk/conferences-and-events/proceedings/proceedings home.cfm?\& ResultsType=Abstracts\&ResultSet_ID=269\&FormDisplayMode=view\&frmShowSelect ed=true\&localAction=details 